\title{
Editorial
}

\section{Library Leadership: Observations and Questions}

Before 1980, articles and books on library leadership were scarce. While doing research for one of the first books (Library Leadership: Visualizing the Future) on the topic, ${ }^{1}$ I could not find any books on library leadership in Books in Print. Perusing issues of Library Literature from 1975 to 1981, I was astonished to find only five entries containing the words leadership and leaders. It is difficult to comprehend why people holding responsible positions in libraries were reluctant to articulate the importance of leadership for so long. However, in recent years, we have witnessed some good pieces on library leadership. For example, Terrence F. Mech and Gerard B. McCabe have assembled an exciting book titled Leadership and Academic Libraries that contains nineteen chapters on different dimensions of academic library leadership. ${ }^{2}$ This book should be added to the reading list of anyone interested in learning more about this topic.

\section{Doing Things Right, or Doing the Right Things}

Too often in our profession, management is perceived as leadership. Managers do things right, whereas leaders do the right things. Managers focus on efficiency, and leaders want to improve effectiveness. Management and leadership are in two different hemispheres, and they should not be viewed as being similar. Moreover, they both are quite important! Managers tend to work within the defined bounds of known quantities, using well-established techniques to accomplish predetermined ends; they tend to stress means and neglect ends. The leader's task to hold, before all persons connected with a library, some vision of what its mission is and how it can be reached more effectively. Managers may be described as being too busy doing the possible to find time to reach for the difficult or impossible. Leadership involves looking forward, as well as inward. The fact is that too many academic libraries are overmanaged and underled!

\section{Anyone can predict anything as long as one does not have to bring the prediction into reality.}

Day-to-day transactional management should not be dismissed as unimportant. Strong managers are needed to support leaders in keeping things moving forward and performed correctly. Notwithstanding the ambiguity associated with the unprecedented rate of change occurring in academic libraries, for some inexplicable reasons, there is a shortage of transformational library leaders who can formulate a compelling vision and make it happen.

\section{Dire Predictions, Reality, and Vision}

To paraphrase T. S. Eliot, there is a giant shadow between an idea (library prediction) and the act (making the prediction happen). Anyone can predict anything as long as one does not have to bring the prediction into reality. Some predictions include digital initiatives causing the demise of paper-based libraries. We hear speakers at conferences and read prognosticators' comments telling us that that the death of the book is near. Ironically, each year, the number of new books pub- 
lished throughout the world exceeds the preceding year.

A compelling vision is necessary in any leader's repertoire. However, it is foolish for anyone to expect to accurately predict what the academic library is going to be twenty years hence. The practice of expounding oversimplified statements by politicians and technology vendors is very dangerous. The public is currently being told by some that within a matter of months, the entire Library of Congress is going to be electronically available to the entire world. Such outrageous statements are dumb and irresponsible, and certainly do not represent credible leadership.

\section{Strategic Thinking}

A clear, articulated vision of the library's future has to be supported by an achievable mission statement that is current and delineates the raison d'être of the library. A library's mission is achieved via strategies (i.e., courses of action). Library leaders and managers should engage in creating, analyzing, and synthesizing strategic scenarios of the library's future. New strategic directions should not be left to happenstance but, rather, should occur through thoughtful preparation and execution. Focus groups, think tanks, and "what if?" groups are examples of ways to involve staff in the strategic envisioning process.

\section{What about the Followers?}

Have you ever read a book or an article on leadership and failed to find any mention of the followers? Who is the leader leading? Can there be leadership without "followership"? These questions deserve specific answers. Based on my readings and observations, "followership" is a critical component of leadership. For followers, leaders offer inspiration, direction, sense of purpose, confidence, and renewal. Followers will determine, to a large extent, the success of the library's realization of its vision and mission. Followers and leaders must work together in questioning the status quo, revisiting the library's assumptions, and clarifying/ refreshing the library's values.

\section{Why Is Risk-Taking So Rare in Academic Libraries?}

It is uncommon to learn about academic libraries promoting risk-taking. Why is this the case? Generally speaking, academic libraries are conservative organizations. They normally operate on insufficient budgets, and are doing more and more with less and less. The reward for giving excellent service is additional work. The more added value we provide our users, the more they expect. Due to a shortage in resources and to increased workloads, there is little or no flexibility for embracing errors. For various reasons,

\section{Can there be leadership without "followership"?}

libraries seldom stop doing things. If budgets remain insufficient, library leaders will have to find ways to innovate by substitution (i.e., stop doing certain things to free up resources for more important initiatives). Libraries should seriously consider developing two new task forces: a "stop-doing" task force to examine what is being done that could be discontinued without any significant impact on current and future service, and a user self-sufficiency task force. Online information services should be designed to be even more user-friendly. For example, intelligent front ends to online resources should be put in place to allow users access to desired information without the intermediation of a librarian. Leadership is tested to find ways to allow more creativity, innovation, entrepreneurship, and risk-taking. Risk takers should be encouraged and recognized. The Hugh C. Atkinson Memorial Award (sponsored by four ALA divisions) is a good example of recognition for risk-taking.

\section{Other Leadership Attributes and Beyond}

This editorial is not intended to be inclusive of the various attributes of academic library leadership. Mentoring, intuition, interpersonal dynamics, intellectual ca- 
pacity, personal traits, and local environment/situation are other very important leadership factors.

As stated at the beginning, we may have been remiss in the past for not giving academic library leadership enough attention, but it will certainly be inexcusable if we continue to do so. There is no more powerful engine driving a library toward excellence and success than its leadership!

DONALD E. RIGGS

\section{Note}

1. Library Leadership: Visualizing the Future, ed. Donald E. Riggs (Phoenix, Ariz.: Oryx Pr., 1982).

2. Leadership and Academic Libraries, ed. Terrence F. Mech and Gerard B. McCabe (Westport, Conn.: Greenwood Pr., 1998). 